\title{
The Influence of Sea Ice on Ocean Heat Uptake in Response to Increasing $\mathrm{CO}_{2}$
}

\author{
C. M. BITZ \\ Atmospheric Sciences, University of Washington, Seattle, Washington \\ P. R. GENT \\ National Center for Atmospheric Research,* Boulder, Colorado \\ R. A. Woodgate \\ Polar Science Center, University of Washington, Seattle, Washington \\ M. M. Holland \\ National Center for Atmospheric Research,* Boulder, Colorado \\ R. LINDSAY \\ Polar Science Center, University of Washington, Seattle, Washington
}

(Manuscript received 24 January 2005, in final form 29 July 2005)

\begin{abstract}
Two significant changes in ocean heat uptake that occur in the vicinity of sea ice cover in response to increasing $\mathrm{CO}_{2}$ are investigated with Community Climate System Model version 3 (CCSM3): a deep warming below $\sim 500 \mathrm{~m}$ and extending down several kilometers in the Southern Ocean and warming in a $\sim 200$-m layer just below the surface in the Arctic Ocean. Ocean heat uptake caused by sea ice retreat is isolated by running the model with the sea ice albedo reduced artificially alone. This integration has a climate response with strong ocean heat uptake in the Southern Ocean and modest ocean heat uptake in the subsurface Arctic Ocean.

The Arctic Ocean warming results from enhanced ocean heat transport from the northern North Atlantic. At the time of $\mathrm{CO}_{2}$ doubling, about $1 / 3$ of the heat transport anomaly results from advection of anomalously warm water and $2 / 3$ results from strengthened inflow. At the same time the overturning circulation is strengthened in the northern North Atlantic and Arctic Oceans. Wind stress changes cannot explain the circulation changes, which instead appear related to strengthened convection along the Siberian shelves.

Deep ocean warming in the Southern Ocean is initiated by weakened convection, which is mainly a result of surface freshening through altered sea ice and ocean freshwater transport. Below about $500 \mathrm{~m}$, changes in convection reduce the vertical and meridional temperature gradients in the Southern Ocean, which significantly reduce isopycnal diffusion of heat upward around Antarctica. The geometry of the sea ice cover and its influence on convection have a strong influence on ocean temperature gradients, making sea ice an important player in deep ocean heat uptake in the Southern Ocean.
\end{abstract}

\section{Introduction}

The uptake of heat by the ocean influences the pattern of surface warming as well as the rate of climate

* The National Center for Atmospheric Research is sponsored by the National Science Foundation.

Corresponding author address: Dr. Cecilia Bitz, Atmospheric Sciences, MS 356140, University of Washington, Seattle, WA 98195-1604.

E-mail: bitz@atmos.washington.edu change resulting from increasing greenhouse gases. Modeling studies show that the polar and subpolar regions regulate deep ocean heat uptake in global warming scenarios (Gregory 2000; Huang et al. 2003). Although sea ice is known to influence the oceanic stability and circulation beneath it (e.g., Gordon and Huber 1984; Martinson 1990; Aagaard and Carmack 1994), changes in deep ocean heat uptake have not previously been related to changes in sea ice. Instead sea ice is well known for it contribution to global warming through ice-albedo feedback (Houghton et al. 2001; Ingram et al. 1989). In this study we investigate the po- 
tential for sea ice to amplify both the atmospheric surface warming over sea ice and the rate of ocean heat uptake.

The warming rate in response to increasing greenhouse gases in models is often highly asymmetric between hemispheres. Manabe et al. (1991) attributed the relatively slow warming in the Southern Hemisphere to the deep vertical mixing of heat in the Southern Ocean, in addition to the greater fraction of ocean area. Manabe et al. also noted vertical convection in the Southern Ocean weakened with increasing $\mathrm{CO}_{2}$ forcing. Gregory (2000) found that weakened convection reduced entrainment of heat into the mixed layer from below, which in turn reduced upward diffusion of heat along isopycnals below the mixed layer. Together these oceanic changes caused considerable warming at depth near Antarctica. Huang et al. (2003) verified the results of Gregory (2000) for the Southern Ocean using an ocean adjoint model. It is noteworthy that Manabe et al. (1991), Gregory (2000), and Huang et al. (2003) did not relate the high ocean heat uptake in the Southern Ocean to changes in sea ice.

Convection in and around the Southern Ocean is thought to weaken because surface heat loss is reduced when the overlying atmosphere warms (Gregory 2000; Huang et al. 2003). However, the ocean surface warms very little in the Antarctic, causing Gregory (2000) to question if the reduction in surface heat loss is a consequence, rather than a cause, of the reduction in convection. The question has remained unanswered. One of the goals of this study is to determine what is the cause of the weakened convection in the Southern Ocean and substantial deep ocean heat uptake there, and how this influences heat exchange with the overlying atmosphere.

A second goal of our study is to investigate the cause of the subsurface warming of the Arctic Ocean under increased greenhouse gases forcing that is seen in many models (e.g., Manabe et al. 1991; Gregory 2000; Raper et al. 2002; Gent and Danabasoglu 2004), and the extent to which this subsurface warming amplifies the sea ice retreat, and surface air temperature increase. The subsurface warming is likely related to an increase in northward ocean heat transport that occurs north of approximately $60^{\circ} \mathrm{N}$ in most models (see Fig. 8 in Holland and Bitz 2003). Strengthened incursions of Atlantic flow into the Arctic Ocean below the surface were also found by Wiebe and Weaver (1999) in a model forced with increasing $\mathrm{CO}_{2}$. Our study investigates the potential for sea ice to influence such heat transport and warming in the Arctic Ocean.

In this study we isolate and identify the climate change caused by reducing the summer sea ice to an extent that is characteristic of global warming scenarios. We initiate this climate change by artificially reducing the sea ice albedo and compare the results to the response of the climate system to increasing $\mathrm{CO}_{2}$.

\section{Experiments}

We use version 3 of the Community Climate System Model (CCSM3; Collins et al. 2006) for a series of experiments to investigate the influence of sea ice on climate sensitivity and ocean heat uptake in global warming. The sea ice component of this model is described in detail by Holland et al. (2006) and Briegleb et al. (2004). The polar climate of the twentieth and twentyfirst centuries in this model is discussed in Meehl et al. (2006) and Holland et al. (2006).

To isolate the climate change forced by a reduction in summer sea ice coverage, we artificially and abruptly reduce the albedo of sea ice (both bare and snow covered). The albedo of ice and snow on land is unchanged. The albedo of sea ice in CCSM3 is decomposed into two spectral bands, denoted visible and infrared, for wavelengths above and below $700 \mathrm{~nm}$. The albedo of each band is parameterized as a function of snow depth, sea ice thickness, and surface temperature. Melt ponds are not explicitly modeled, but their influence is parameterized crudely by the dependence of the albedo on temperature. In our integration, we reduce the visible (infrared) albedo when the sea ice is snow covered by $0.08(0.05)$ and when the sea ice is bare by $0.12(0.06)$. Although the reductions are applied in all seasons, their influence is greatest in summer as they cause the sea ice to melt earlier and faster, which in turn causes the seasonal ice area to expand and the mean ice thickness and concentration to decline. These reductions are not meant to represent any realistic physical change to the sea ice. Instead, the albedo is lowered in an attempt to reproduce approximately the same minimum summertime ice cover as reached at equilibrium when $\mathrm{CO}_{2}$ is twice the 1990s level. Reducing the albedo accomplishes this ice-cover reduction without creating an imbalance in the surface fluxes, which is not the case if the sea ice reduction itself is prescribed. Moreover, reducing the albedo does not inhibit feedbacks in the climate system, although the magnitude of ice-albedo feedback is likely reduced somewhat. The amount the albedo must be reduced was determined from a series of experiments with a slab ocean model, rather than the full ocean general circulation model, so an equilibrium was reached in only a few decades. We then carried out an integration with a full ocean general circulation 

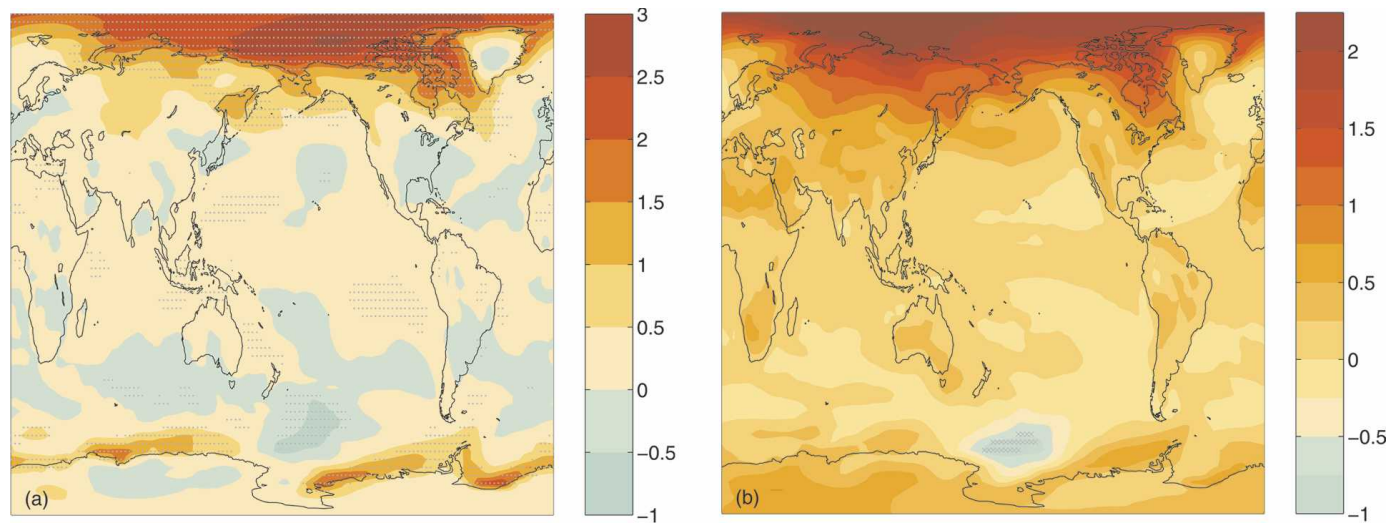

FIG. 1. Change in 2-m surface air temperature in ${ }^{\circ} \mathrm{C}$ resulting from (a) lowering sea ice albedo and (b) doubling $\mathrm{CO}_{2}$, compared to the control. In (a), the gray dots mark grid cells with statistically significant warming or cooling $(p=0.95)$. In (b), gray Xs mark grid cells with significant cooling. Nearly all other grid cells in (b) have significant warming.

model, where we reduced the ice albedo at the start and integrated the model for 100 yr. In section 3 we show that the experiment gives about the right reduction in sea ice cover.

Hansen and Nazarenko (2004) estimated the effect of increasing soot on sea ice by decreasing the sea ice albedo, but only by a few percent, compared to our $\sim 8 \%$ reduction. They found that for a given change in radiative forcing (the net radiation at the top of the model atmosphere), reducing the sea ice albedo is about twice as effective as increasing $\mathrm{CO}_{2}$ in altering global surface air temperature. Our albedo reduction is much larger than theirs and is not intended to represent the effects of soot. Instead we attempted to create a reduction in sea ice cover comparable to that which occurs in response to the radiative forcing of doubling $\mathrm{CO}_{2}$. In addition our experiment is conducted with an ocean general circulation model, while Hansen and Nazarenko (2004) used a slab ocean model with diffusive mixing of heat into the deep ocean.

In this study, the albedo reduction experiment is compared to a control integration with 1990s forcing conditions (Collins et al. 2006). Additionally, the response to reducing the sea ice albedo is compared to the response in a pair (two ensemble members) of integrations with increasing $\mathrm{CO}_{2}$, which we average and, for simplicity, refer to as a single case. $\mathrm{CO}_{2}$ was increased at the rate of $1 \% \mathrm{yr}^{-1}$ for $160 \mathrm{yr}$. The analysis presented here includes only output from the first $80 \mathrm{yr}$, although we did analyze the full 160-yr record. $\mathrm{CO}_{2}$ doubles in year 70 of the $\mathrm{CO}_{2}$ ramp runs, so most of our discussion is confined to years $60-80$, which we refer to as the time of $\mathrm{CO}_{2}$ doubling. We present results from the same period of the sea ice albedo reduction integration, which is an average of $60-80 \mathrm{yr}$ after the albedo was abruptly reduced. To avoid confusing long-term spinup transients with forced transients, we compare output from the forced runs and the controls in the same years after initiating $\mathrm{CO}_{2}$ forcing or the sea icealbedo reduction from their respective controls.

\section{Results}

\section{a. 2-m air temperature}

In response to reducing the sea ice albedo, the change in 2-m air temperature, shown in Fig. 1a, has a strong hemispheric asymmetry when averaged over years $60-80$ of the integration. The warming is about $2{ }^{\circ} \mathrm{C}$ over sea ice in the Arctic, but just $0.5^{\circ} \mathrm{C}$ over sea ice in the Antarctic. While all areas with significant temperature change in the Northern Hemisphere are warmer, the Southern Hemisphere has about equal areas of significant cooling and significant warming. The asymmetry of the warming in response to reducing the sea ice albedo is even greater than the asymmetry of the warming that results in the $\mathrm{CO}_{2}$ ramp run (see Fig. 1b) at the time of $\mathrm{CO}_{2}$ doubling (average of years $60-80$ in the $\mathrm{CO}_{2}$ ramp run).

Note that reducing the albedo only directly contributes to reducing the ice coverage when there is sunlight. However, the surface may still be anomalously warm in winter if the ice is thinner and/or its area is reduced, or if additional heat is stored in the upper ocean from solar radiation absorbed during summer. Indeed most of the warming in Fig. 1a occurs during the cold season, although the shortwave radiation changes most in summer.

The slight, but significant, cooling north of the Ross Sea in Fig. 1b is noteworthy. Most climate models exhibit a local warming minimum somewhere in the 

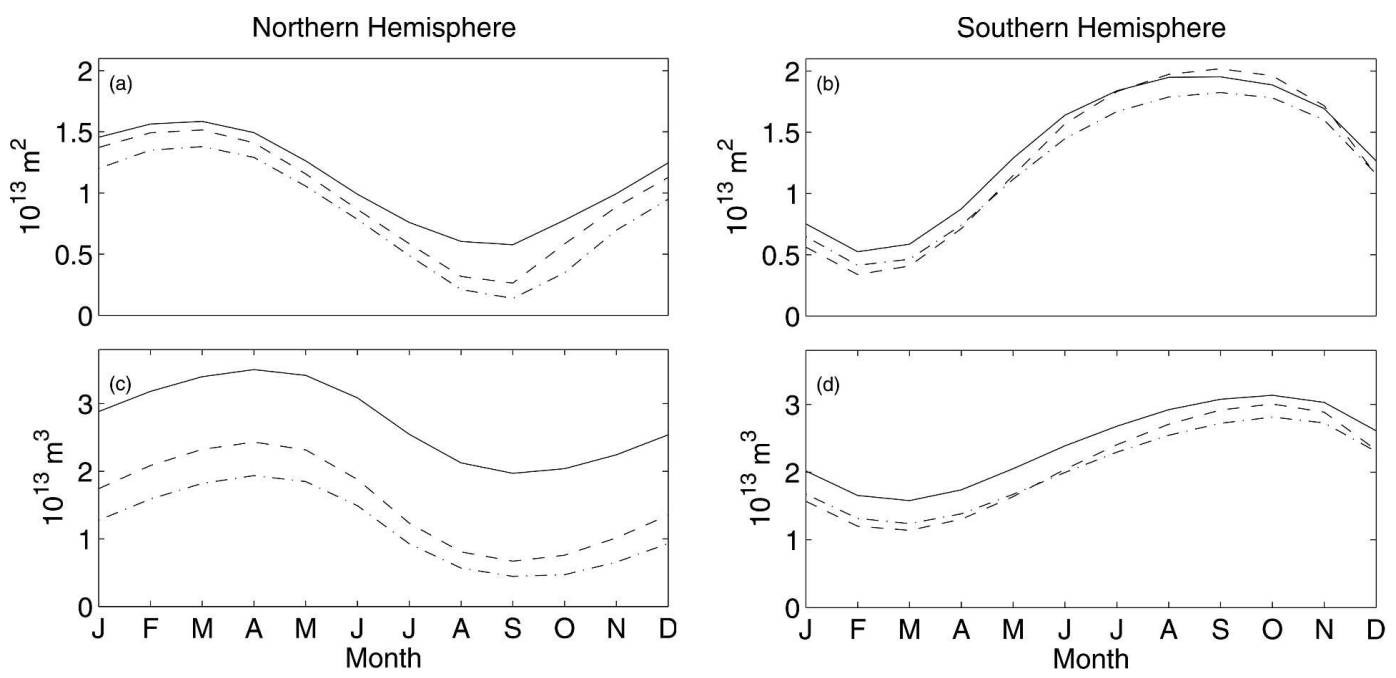

FIG. 2. Climatological mean annual cycle of (a), (b) ice area and (c), (d) ice volume in the Northern and Southern Hemispheres. Curves are for control (solid), reducing the sea ice albedo (dashed), and doubling $\mathrm{CO}_{2}$ (dot-dash) experiments.

Southern Ocean in response to increasing greenhouse gases (Houghton et al. 2001). Such warming minima have been attributed to deep mixing and weakened convection (see introduction). It would appear that similar processes are at play when the sea ice albedo is reduced, in Fig. 1a. The near total lack of warming anywhere in the Southern Hemisphere when the sea ice albedo is reduced suggests that if convection is weaker, it is not a consequence of surface warming. Before describing the ocean response in our two experiments, we present a short summary of the sea ice response.

\section{b. Sea ice}

Figure 2 shows the climatological mean annual cycle of the sea ice area and volume by hemisphere for control, reduced sea ice, and $\mathrm{CO}_{2}$ doubling experiments. The sea ice albedo reduction was chosen to produce approximately the same summer minimum ice coverage at equilibrium as doubling $\mathrm{CO}_{2}$. Figures $2 \mathrm{a}$,b show the extent to which this goal was attained after just $60-80$ yr. Compared to doubling $\mathrm{CO}_{2}$, reducing the sea ice albedo causes the summer minimum ice cover to be too low by about $0.1 \times 10^{13} \mathrm{~m}^{2}$ in the Southern Hemisphere and too high by a similar amount in the Northern Hemisphere

A similar response is seen in the ice volume-with summer ice volume decreasing more by reducing the sea ice albedo than doubling $\mathrm{CO}_{2}$ in the Southern Hemisphere, and vice versa in the Northern Hemisphere. Interestingly, reducing the sea ice albedo has a large effect on winter ice volume only in the Northern Hemisphere, where perennial ice thins during summer and remains thinner throughout the following winter. The small amount of perennial ice in the Southern Hemisphere prevents this kind of persistence from dominating there.

\section{c. Global ocean heat uptake}

Figure 3a shows the zonal mean potential temperature change in the global oceans in response to reducing the sea ice albedo. Like the surface air temperature change, the upper ocean temperature change also has a strong hemispheric asymmetry. The temperature change in the ocean mixed layer (above the white line in Fig. 3a) everywhere south of about $45^{\circ} \mathrm{N}$ is in the range of $\pm 0.1^{\circ} \mathrm{C}$. In contrast the mixed layer warms by about $0.5^{\circ} \mathrm{C}$ from $45^{\circ}-75^{\circ} \mathrm{N}$. The peak warming is in the Arctic at about $0.7^{\circ} \mathrm{C}$ just beneath the mixed layer. Perhaps most interesting is the deep warming centered at about 2-km depth in the Southern Ocean, with a maximum of $0.6^{\circ} \mathrm{C}$. No substantial warming occurs below 1 $\mathrm{km}$ in the Arctic Ocean.

In response to doubling $\mathrm{CO}_{2}$, the potential temperature change in CCSM3 (Fig. 3b) has features in common with other models (e.g., Manabe et al. 1991; Gregory 2000; Raper et al. 2002; Flato et al. 2000). Deep vertical mixing in the Southern Ocean distributes surface heating through a deep layer and delays warming of the mixed layer compared to elsewhere, so the upper ocean there warms relative little by the time of $\mathrm{CO}_{2}$ doubling. In addition, vertical convection weakens, which reduces entrainment of heat into the mixed layer from below (Manabe et al. 1991). Warming below $1 \mathrm{~km}$ is greatest in the Southern Ocean, which has been at- 

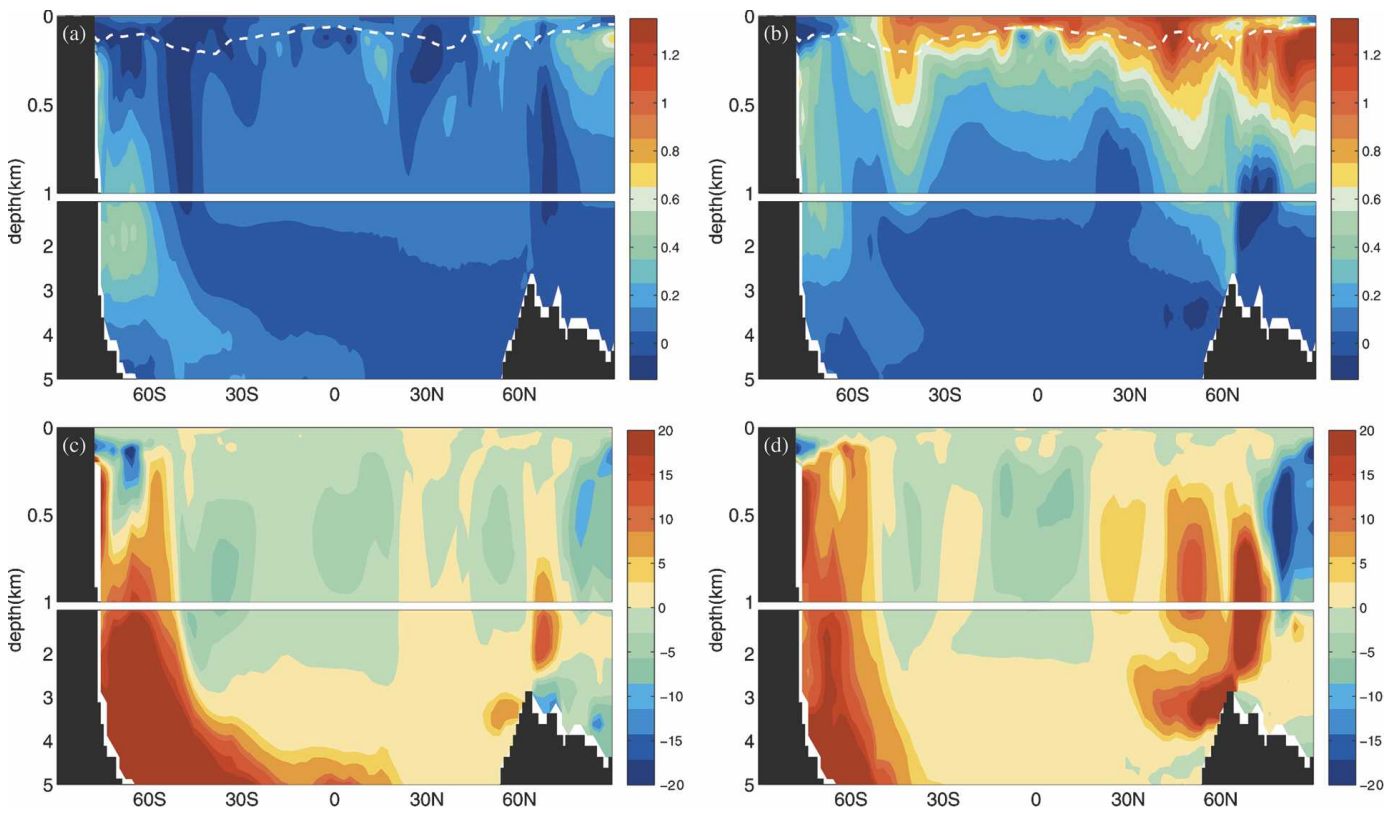

FIG. 3. The change in (upper) zonal mean ocean potential temperature in ${ }^{\circ} \mathrm{C}$ and (lower) ocean ideal age in yr resulting (left) from reducing sea ice albedo and (right) from doubling $\mathrm{CO}_{2}$. Dashed line shows zonal mean of the maximum mixed layer depth from the 1990s control climatological mean annual cycle.

tributed to reduced upward diffusion along isopycnal surfaces below the mixed layer (Gregory 2000). The warming in the upper $1 \mathrm{~km}$ but below the mixed layer in the Tropics results from reduced upwelling strength, as the Meridional Overturning Circulation (MOC) is weaker throughout most of the World Ocean in the warmer climate (Manabe et al. 1991). The very intense warming in the Arctic is typical of models that employ the Gent-McWilliams mixing scheme (Wiebe and Weaver 1999; Gent and Danabasoglu 2004).

Comparing the potential temperature change in response to reducing the sea ice albedo and doubling $\mathrm{CO}_{2}$ (Figs. 3a,b), we see many features in common below about 1-km depth. Compared to doubling $\mathrm{CO}_{2}$, the reduced sea ice albedo case has greater deep ocean warming in the Southern Ocean and less upper ocean warming in both hemispheres. The pattern of warming just below the surface in the Arctic Ocean is quite similar in either case, although the magnitude is much smaller in the reduced sea ice albedo case. The relative magnitude of the warming asymmetry in the ocean in response to these two cases is consistent with the magnitude of sea ice thinning. Recall that the Northern Hemisphere sea ice volume change is larger in response to doubling $\mathrm{CO}_{2}$ than reducing the sea ice albedo (Fig. 2c), while the sea ice volume change is more comparable in the Southern Hemisphere (Fig. 2d).

In either experiment, the considerable warming at depth in the Southern Ocean is isolated from the Ant- arctic sea ice, where it might enhance melting. The subsurface warming in the Arctic is much nearer to the surface and even reaches the surface in the Barents Sea in the $\mathrm{CO}_{2}$ doubling case, at locations where sea ice is present in the 1990s control run.

Evidence of reduced deep water production in the mid- to high latitudes is seen from the change in ideal age shown in Figs. 3c,d. Ideal age is a tracer of the time since seawater has been at the surface (Bryan et al. 2006). An increase in ideal age at depth is an indication of reduced deep water formation. The increase in ideal age from $30^{\circ}-70^{\circ} \mathrm{N}$ at $\mathrm{CO}_{2}$ doubling in particular (Fig. $3 \mathrm{~d}$ ) is evidence of a weakening of the thermohaline circulation, which is confirmed by a reduction in the meridional streamfunction in the North Atlantic (Bryan et al. 2006). The ideal age increase around Antarctica indicates that vertical mixing and deep or bottom water formation is reduced.

There is a shallow region hugging the Antarctic continent where the water is younger in Figs. 3c,d. Reducing sea ice albedo produces younger water in the upper ocean at about $60^{\circ}-70^{\circ} \mathrm{S}$ too. These regions with younger water do not span the whole latitude circle, rather they are small-scale but large enough in magnitude to affect the zonal mean. (Section 3d includes more detail about horizontal patterns of ideal age in the Southern Ocean.) The upper ocean of the Tropics appears slightly younger as a result of weakened upwelling there. These changes in vertical advection and 
mixing that are inferred from the ideal age fit well with the interpretation of changes in circulation drawn from ocean temperature in Figs. 3a,b.

Another area that deserves further scrutiny is the upper $1 \mathrm{~km}$ of the Arctic Ocean in Fig. 3. A question arises from these model results: Could it be that the subsurface Arctic warming results from an increase in horizontal heat transport, which, as mentioned in the introduction, occurs in most global climate models when forced with increasing $\mathrm{CO}_{2}$ ? Indeed, the zonal mean northward heat transport in the global oceans in CCSM3 (Fig. 4; the combined Eulerian mean plus eddy or bolus heat transport) increases north of about $60^{\circ} \mathrm{N}$ in both perturbation experiments. Figure 5 shows the change in zonal mean heat flux, with the sign convention such that a positive change is an increase in ocean heating or a decrease in heat loss as is the case in the polar regions during winter. Interestingly, Fig. 5 indicates that in the Arctic, the surface loses more heat to the atmosphere (north of $70^{\circ} \mathrm{N}$ in the reduced sea ice albedo experiment and north of $80^{\circ} \mathrm{N}$ in the $\mathrm{CO}_{2}$ doubling experiment) despite the increase in absorbed shortwave radiation as the sea ice cover retreats and thins. Therefore changes in the surface heat flux cannot directly be responsible for the ocean warming. In section $3 \mathrm{e}$ we further analyze these changes in the Arctic.

In both cases, we see an increase in the surface flux into the Southern Ocean (Fig. 5), while horizontal heat transport is nearly unchanged south of $60^{\circ} \mathrm{S}$. This results from increased absorbed shortwave radiation in summer without a compensating loss of heat during in winter. This is consistent with the strong reduction in sea ice coverage in summer only. In addition, the substantial increase in northward heat transport north of about $60^{\circ} \mathrm{S}$ serves to remove heat from about $50^{\circ}-60^{\circ} \mathrm{S}$ and deposit it at about $40^{\circ}-50^{\circ} \mathrm{S}$.

These significant amounts of ocean heat uptakebelow about $500 \mathrm{~m}$ and extending down very deep in

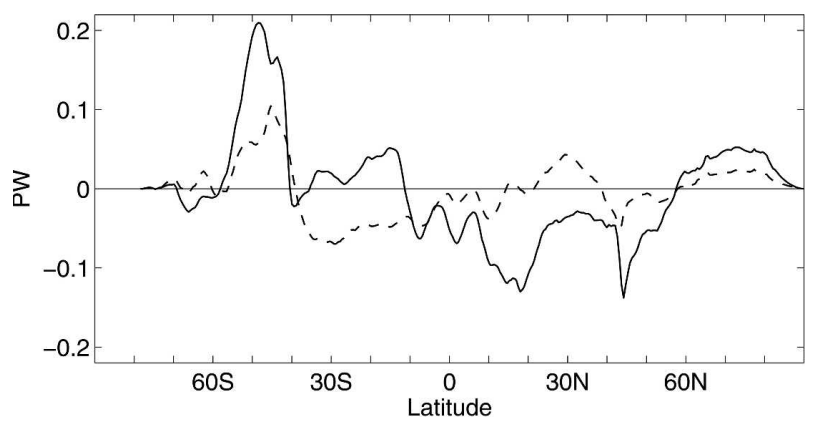

FIG. 4. The change in zonal mean northward heat transport into the global oceans resulting from doubling $\mathrm{CO}_{2}$ (solid) and lowering sea ice albedo (dashed).

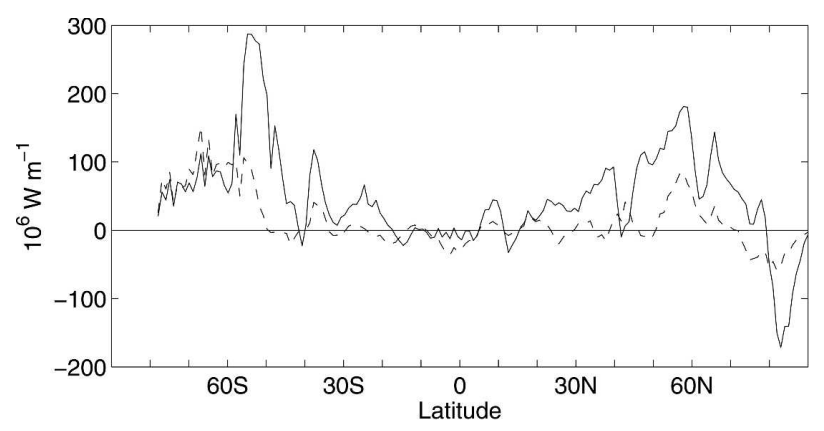

FIG. 5. The change in zonal mean surface heat flux in the global oceans resulting from doubling $\mathrm{CO}_{2}$ and lowering sea ice albedo (dashed). Curves are integrated along latitude circles. A positive change in the surface heat flux is a source of heat to the ocean.

the Southern Ocean and in a 200-m layer just below the surface in the Arctic-appear in the vicinity of sea ice cover. Generally the sign and pattern of change in Figs. 3-5 in the polar regions are the same for either doubling $\mathrm{CO}_{2}$ or reducing sea ice albedo, although the magnitude differs. Compared to doubling $\mathrm{CO}_{2}$, reducing the sea ice albedo has larger deep ocean warming and ideal ocean age increase in the Southern Ocean and smaller upper ocean warming and ideal ocean age decrease in the Arctic. These relative differences are consistent with the relative changes in the sea ice shown in Fig. 2.

\section{d. Ocean heat uptake in the Southern Ocean}

In this section we describe the mechanism that gives rise to the Southern Ocean warming in CCSM3. Gregory (2000) found warming below the mixed layer is initiated by reduced convection in the Second Hadley Center Coupled Ocean-Atmosphere General Circulation Model (HadCM2) when forced with increasing $\mathrm{CO}_{2}$. The analysis presented so far using CCSM3 supports Gregory's findings, but in addition we find that reducing the sea ice albedo alone efficiently warms the deep Southern Ocean, apparently also by weakening convection. This latter result is evidence that retreating sea ice, albeit modestly, could be responsible for weakening the convection. Next we further describe how convection weakens in our experiments. Then we describe how weakened convection leads to warming at depth in the Southern Ocean.

\section{1) WeAKENED CONVECTION}

Reduced convection in the Southern Ocean most likely results from increased buoyancy in the surface waters. Later we show that reduced convection is most important in the vicinity of about $55^{\circ}-70^{\circ} \mathrm{S}$. Figure $6 \mathrm{a}$ 

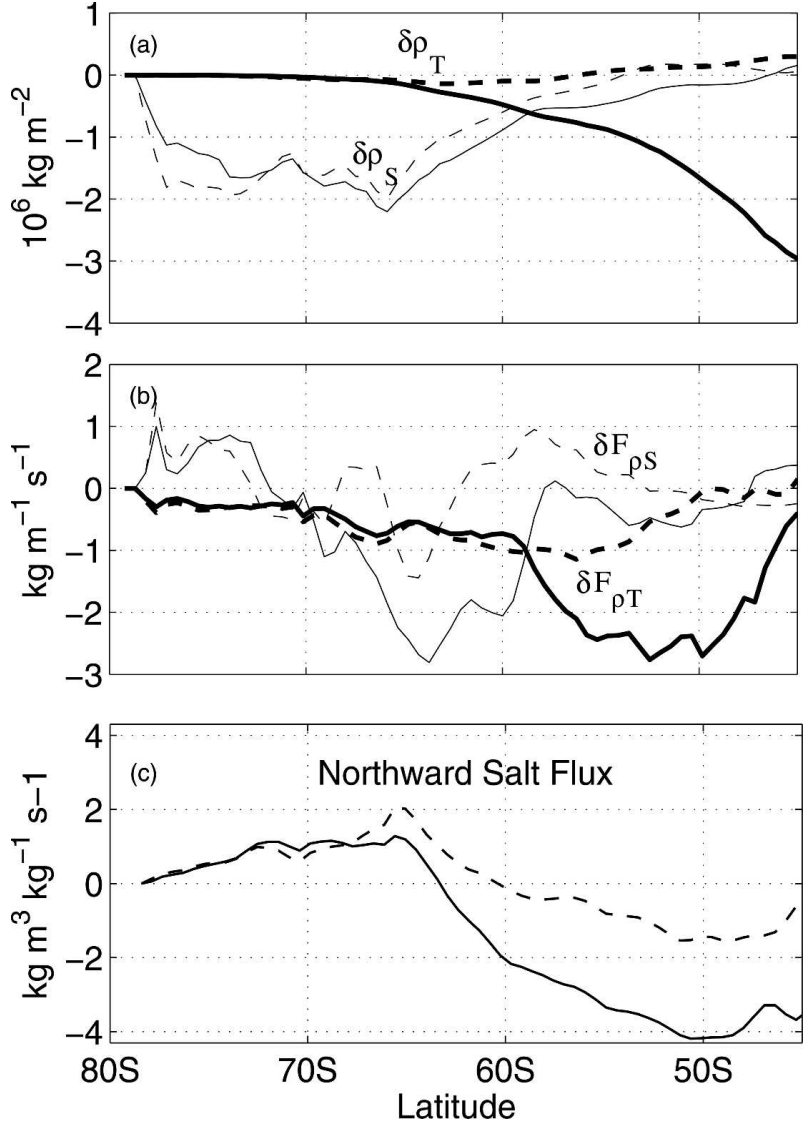

FIG. 6. Change in (a) zonal mean surface density contributed from the change in sea surface temperature $\left(\delta \rho_{T}\right.$, bold lines) and salinity ( $\delta \rho_{S}$, light lines). Change in (b) zonal mean surface density flux from heat flux $\left(\delta F_{\rho T}\right.$, bold lines) and freshwater fluxes $\left(\delta F_{\rho S}\right.$, light lines). Change in (c) zonal mean northward salt flux. Changes in response to doubling $\mathrm{CO}_{2}$ are solid lines, and reducing sea ice albedo are dashed.

shows the change in surface density contributed alternately from temperature and salinity $\left(\delta \rho_{T}\right.$ and $\delta \rho_{S}$, respectively), using Eq. (2) from Bryan et al. (2006). The surface density is reduced by freshening at the surface from the Antarctic coast to about $60^{\circ} \mathrm{S}$ in both perturbation experiments. The contribution from the temperature change is insignificant in the reduced albedo case, and it is only substantial north of $\sim 60^{\circ} \mathrm{S}$ in response to doubling $\mathrm{CO}_{2}$. The temperature component is small in the Southern Ocean in part because the thermal expansion of seawater is small near the freezing temperature.

Changes in the surface heat and freshwater fluxes are candidates to explain changes in the surface density. Figure $6 \mathrm{~b}$ shows their individual contribution in the form of a density flux using Eq. (3) from Bryan et al. (2006). The change in density flux from the surface heat flux $\left(\delta F_{\rho T}\right)$ is negative (tending to increase ocean sta- bility) in the zonal mean, due to the increase in (downward) surface heat flux in Fig. 5, mostly from increased absorbed solar radiation. However, consistent with the small magnitude of $\delta \rho_{T}, \delta F_{\rho T}$ probably only contributes substantially to weakening convection north of $60^{\circ} \mathrm{S}$ in response to doubling $\mathrm{CO}_{2}$ and not much at all in the reduced albedo experiment. Horizontal maps of $\delta F_{\rho T}$ (not shown) do not reveal any local regions with considerably higher magnitude.

The density flux from the surface freshwater flux $\left(\delta F_{\rho S}\right)$ acts to stabilize the surface from $\sim 58^{\circ}-70^{\circ} S$ in response to doubling $\mathrm{CO}_{2}$, but it does little in the reduced albedo experiment. In either case, the net salt flux at the surface south of $70^{\circ} \mathrm{S}$ actually increases owing to higher sea ice growth rates (ice growth depends inversely on thickness) and greater divergence away from the continent (not shown). Freshening from $\delta F_{\rho S}$ north of $70^{\circ} \mathrm{S}$, especially in response to doubling $\mathrm{CO}_{2}$, occurs where ice convergence increases. Further freshening south of $65^{\circ} \mathrm{S}$ results from advective changes. Figure $6 c$ shows the change in the zonal mean northward salt transport is positive (salt is exported) south of $65^{\circ} \mathrm{S}$.

In summary increased stability from about $55^{\circ}-70^{\circ} \mathrm{S}$ results mainly from freshening at the surface due to increased sea ice convergence and advection in the ocean. Increased heat flux into the ocean has a negligible influence, except north of about $60^{\circ} \mathrm{S}$ in the $\mathrm{CO}_{2}$ ramping experiment.

\section{2) WARMing AT DEPTH}

To understand how weakened convection alters temperatures at depth, recall that the vertical temperature profile in the Southern Ocean exhibits a temperature maximum at about $500 \mathrm{~m}$ (see Fig. 7). As convection weakens, there is less entrainment of water from this warmer layer into the mixed layer, so the temperature maximum intensifies further. Hence, below the mixed layer we expect that altered convection should result in a positive correlation between the change in ideal age and temperature in the Southern Ocean (see Fig. 3).

Figures $8 \mathrm{a}, \mathrm{c}$ show the change in temperature and the ocean ideal age at 580-m depth around Antarctica in response to reducing the sea ice albedo. The water between Antarctica and the Antarctic Circumpolar Current (ACC) is considerably warmer and older in three somewhat distinct patches, one in each ocean sector (Atlantic, Indian, and Pacific), with the greatest increase in temperature and age occurring in the Atlantic sector. The water is cooler and younger in a narrow swath just to the north of the warmer-older patch in the Atlantic sector and in three small spots along the Antarctic continent between the warmer-older patches. The cooler-younger swath in the Atlantic marks a local 

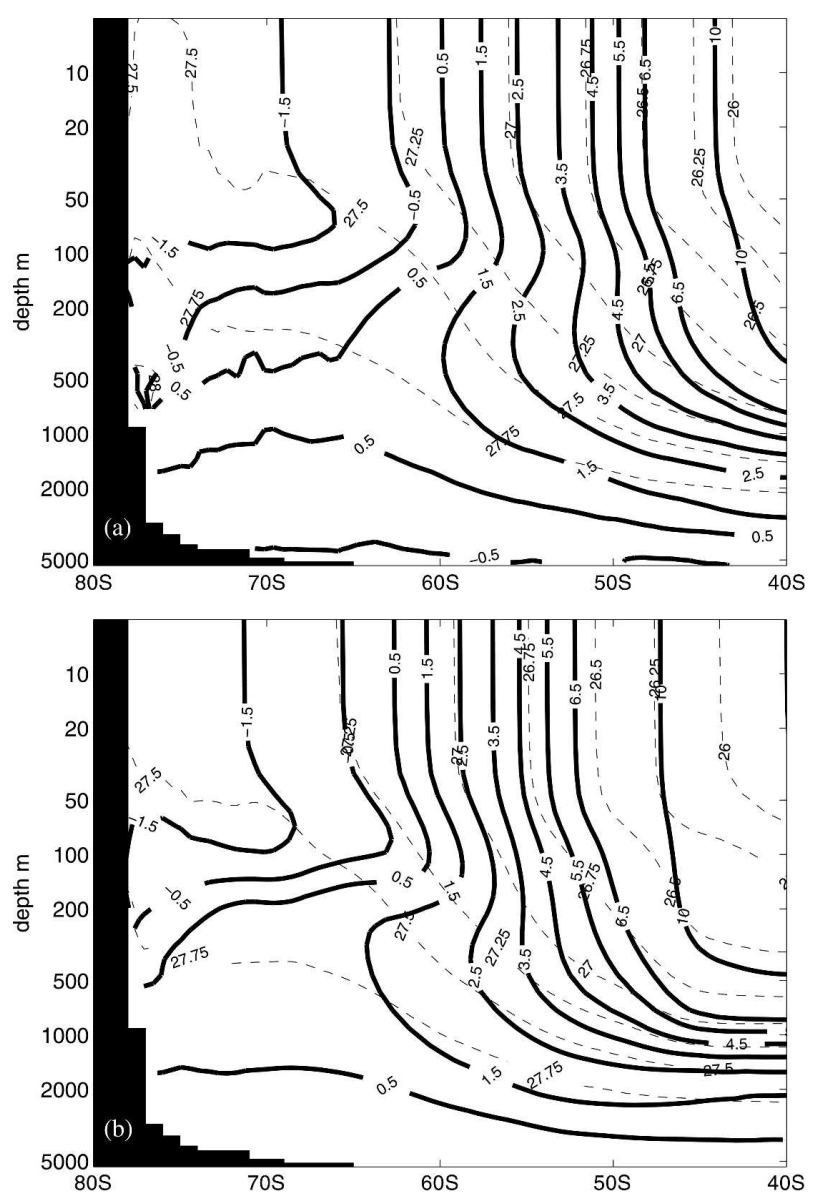

FIG. 7. Zonal mean potential temperature (solid) in ${ }^{\circ} \mathrm{C}$ and potential density contours (dashed) in $\mathrm{kg} \mathrm{m}^{-3}$ in the control integration from $40^{\circ}$ to $80^{\circ} \mathrm{S}$; (a) averaged for all longitudes, (b) averaged in the vicinity of the Ross Sea only $\left(130^{\circ} \mathrm{W}\right.$ to $\left.180^{\circ}\right)$.

increase in convection, which results from reduced ice transport to the ice edge. The relationship between age and temperature is strongest south of the ACC. The most obvious departure from the positive correlation between temperature and ideal age occurs in the Pacific sector north of the ACC. There the vertical temperature profile lacks the temperature maximum at 500-m depth at $\sim 55^{\circ} \mathrm{S}$ (Fig. 7b) that is present elsewhere around Antarctica at the same latitude (Fig. 7a), so the anomalous temperature-ideal age relationship breaks down.

South of the ACC, the changes in temperature and ideal age at $580 \mathrm{~m}$ in response to doubling $\mathrm{CO}_{2}$ (see Figs. $8 \mathrm{~b}, \mathrm{~d}$ ) are very similar to the response to reducing the sea ice albedo (see Figs. 8a,c). However, at midlatitudes, large ocean warming is found in response to ramping $\mathrm{CO}_{2}$ where little warming occurs in the reduced sea ice albedo case.

In general, isopycnals slope upward to the south (Fig.
7) and the temperature along these isopycnals decreases southwards at all depths and upward between 100-500-m depth. Diffusion of heat along isopycnal surfaces, where isotherms intersect isopycnals, cools the deep ocean efficiently. Warming below the mixed layer, as is seen in Figs. 8a, b, reduces the temperature gradient along isopycnal surfaces below the mixed layer (see Fig. 7a), which then gives rise to reduced isopycnal diffusion (Gregory 2000). However, isopycnal diffusion can also be altered by changes in the meridional temperature gradient, which is considerably reduced at 580-m depth from the ACC southward in Figs. 8a,b (both experiments).

Following Gregory (2000), we estimate change in isopycnal diffusion from the vertical and meridional temperature gradients independently. Both experiments have about the same change from vertical temperature gradients at 580-m depth, but the change from meridional temperature gradients is considerably higher in the reduced sea ice albedo case. Thus, the isopycnal diffusion is reduced more, and in turn the deep ocean warms more, in the lowered sea ice albedo experiment than in $\mathrm{CO}_{2}$ doubling.

Figure 9 shows the change in temperature and ideal age at $2.125-\mathrm{km}$ depth, which we attribute to reduced isopycnal diffusion and reduced deep and bottom water formation. The changes are larger in response to reducing the sea ice albedo, compared to doubling $\mathrm{CO}_{2}$, as expected from the meridional temperature gradient argument. We believe the meridional temperature gradient decreases more in the reduced albedo case owing to the regional nature of the forcing perturbation.

The spatial patterns of the temperature and ideal age change at $2.125-\mathrm{km}$ depth (Fig. 9) indicate that increased deep ocean heat uptake in both experiments depends on mechanisms south of the ACC, which is mostly ice-covered in winter. The relative homogeneity of the pattern south of the ACC, in contrast to 580-m depth, results from processes that give rise to greater homogeneity at depth. The spatial pattern at $580-\mathrm{m}$ depth (Fig. 8), highlights the regions where convection changes. The remarkable similarity of the pattern in response to either forcing indicates that the declining sea ice cover (which alone initiates the change in the reduced sea ice albedo experiment) plays a key role.

\section{e. Horizontal heat transport into the Arctic}

In this section we analyze the Arctic Ocean warming in more detail. We have already argued that Figs. 4 and 5 indicate that the Arctic Ocean warming is advective. Now we aim to show what drives this advection. We focus on the $\mathrm{CO}_{2}$ ramp run because the Arctic Ocean 

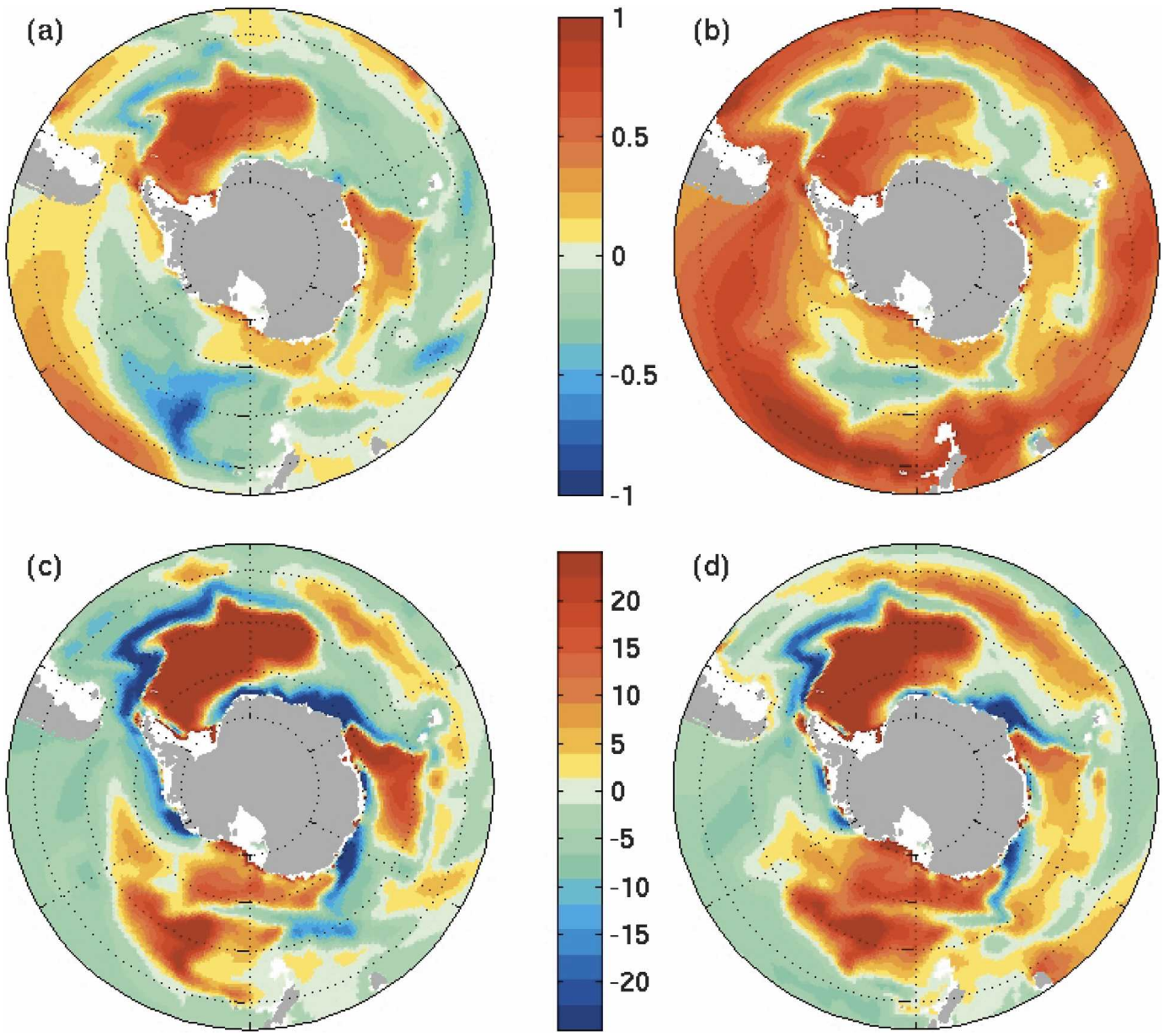

FIG. 8. Change in (a), (b) potential temperature in ${ }^{\circ} \mathrm{C}$ and (c), (d) ocean ideal age in yr at 580-m depth in response to (a), (c) lowering sea ice albedo and (b), (d) doubling $\mathrm{CO}_{2}$.

warming is much larger in response to doubling $\mathrm{CO}_{2}$ than reducing the sea ice albedo. At the end of this section, we explain why reducing the sea ice albedo results in less Arctic Ocean warming.

Northward heat transport, such as shown in Fig. 4, is not well suited to illustrate heat transport into the Arctic from the northern North Atlantic. Because it is averaged along latitude circles, the heat transport at say $80^{\circ} \mathrm{N}$ includes not only northward heat transport from the Greenland-Iceland-Norwegian (GIN) seas but also northward heat transport from the Beaufort Sea. A better projection is shown in Fig. 10a along a line from Iceland to the Siberian Coast. Figure 10b shows the overturning circulation for the control simulation along this line, where as usual the volume transport is computed through surfaces that are normal to the line. About $4 \mathrm{~Sv}$ of the Atlantic overturning circulation penetrates into the GIN seas, of which about 1 Sv reaches into the Arctic Ocean. The heat transport (Fig. 10c) associated with this overturning is $\sim 0.2 \mathrm{PW}$ in the GIN seas.
Figure 11 shows the overturning anomaly resulting from ramping $\mathrm{CO}_{2}$ in 20-yr averages in three successive time intervals. The overturning circulation in the Arctic gradually strengthens for the first $\sim 50 \mathrm{yr}$, but then begins to gradually weaken again. The overturning anomaly into the Arctic Ocean remains positive above 1-km depth for at least $160 \mathrm{yr}$

The Atlantic overturning circulation south of Iceland weakens over time, and the reduction impinges on the higher latitudes, but mostly only below about $1 \mathrm{~km}$ in the Arctic Ocean. We interpret Fig. 11 as indicating that the Atlantic thermohaline circulation weakens but penetrates further into the Arctic. Associated with the strengthened overturning in the Arctic, we see heat transport into the Arctic Ocean increasing gradually, reaching 0.04 PW at the North Pole at $\mathrm{CO}_{2}$ doubling (i.e., years 60-80, which is the solid line in Fig. 12a). Beyond $80 \mathrm{yr}$, the heat transport anomaly remains comparably steady through year 160 . Compared to the control run (see Fig. 10c), The heat transport at $\mathrm{CO}_{2}$ dou- 

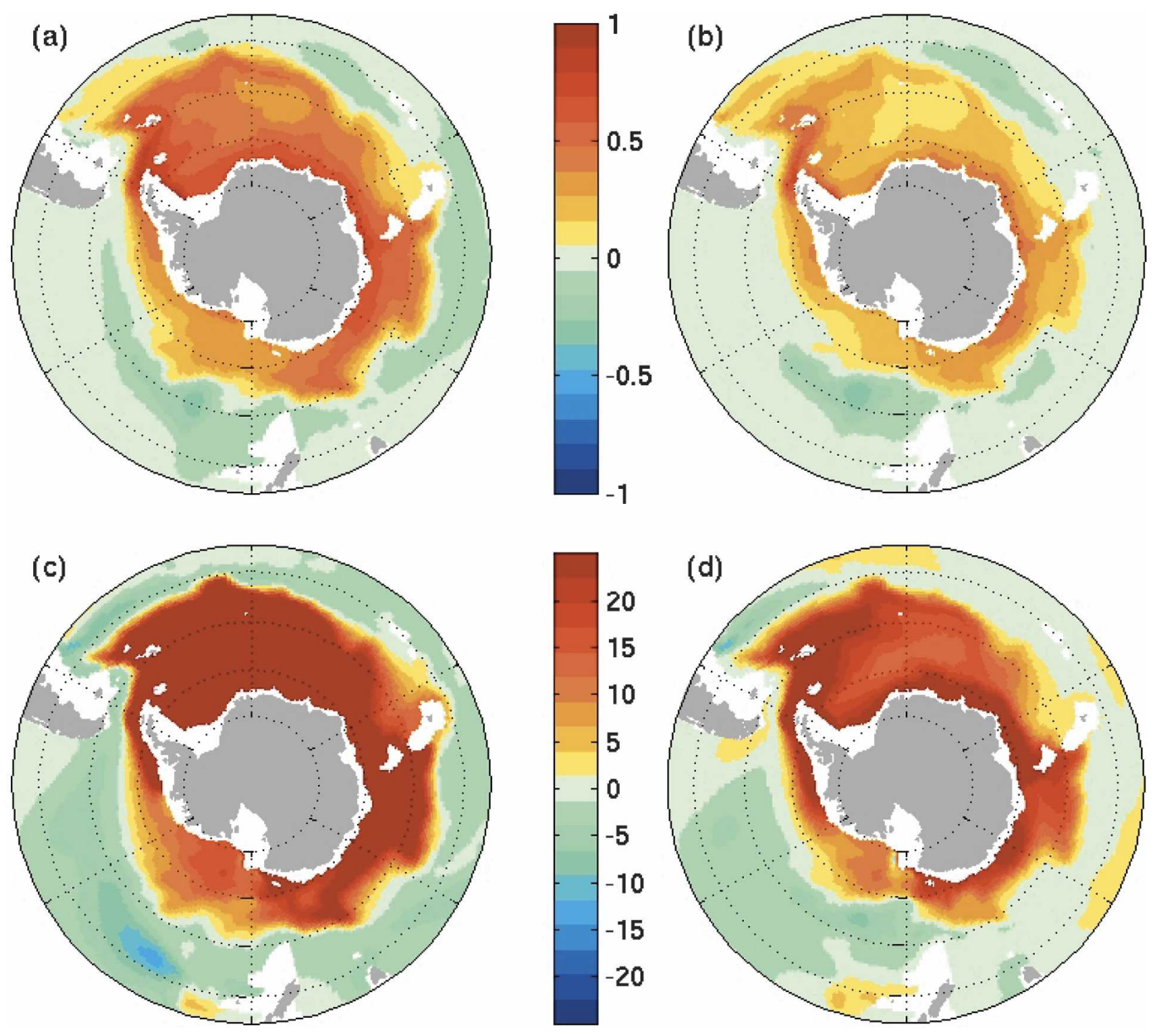

FIG. 9. As in Fig. 8 but for $2.125-\mathrm{km}$ depth.

bling (see Fig. 12a) increases by about 30\% at Fram Strait and more than $100 \%$ at the North Pole.

If we estimate the heat transport anomaly is on average $0.02 \mathrm{PW}$ over the 70 -yr period taken to reach $\mathrm{CO}_{2}$ doubling, then it could deposit $4 \times 10^{9} \mathrm{~J} \mathrm{~m}^{-2}$ uniformly over an area of $10^{7} \mathrm{~km}^{2}$, which is approximately the size of the Arctic Ocean. In contrast, the amount of heat needed to warm a $200-\mathrm{m}$ layer by $1^{\circ} \mathrm{C}$ (roughly the Arctic Ocean warming of Fig. 3b) is only $0.8 \times 10^{9} \mathrm{~J}$ $\mathrm{m}^{-2}$. Hence some of the heat transported horizontally must be lost to the ice and atmosphere. If this much heat could reach the sea ice alone, it would melt the entire ice cover in less than a decade!

The heat transport change may be broken into independent components resulting from the anomalous temperature of the advected water $T^{\prime}$ and the anomalous current velocity $\mathbf{v}^{\prime}$ :

$$
\left(\mathbf{v}+\mathbf{v}^{\prime}\right)\left(T+T^{\prime}\right)-\mathbf{v} T \sim \mathbf{v}^{\prime} T+\mathbf{v} T^{\prime},
$$

because $\mathbf{v}^{\prime} T^{\prime}$ is small. These components for the 40-60yr interval of $\mathrm{CO}_{2}$ ramping experiments, contribute about $2 / 3$ from the anomalous current velocity $\mathbf{v}^{\prime} T$ and about $1 / 3$ from the anomalous temperature $\mathbf{v} T^{\prime}$ (see Fig. 12b). During the 60-80-yr interval the components contribute about equal portions (not shown), as the anomalous temperature increases while the anomalous current velocity stays about the same.

The anomalous current could be driven by buoyancy forcing and/or wind stress. While the anomalous wind is southerly in the GIN seas, the anomalous surface currents in the GIN seas are quite small and become southward by $\mathrm{CO}_{2}$ doubling. In addition, the barotropic streamfunction weakens in the $\mathrm{CO}_{2}$ ramp run (not shown). Moreover, $\mathbf{v}^{\prime} T$ stops increasing by about $\mathrm{CO}_{2}$ doubling, while the winds continue to strengthen. For these reasons, we argue that the anomalous subsurface current that flows into the Arctic must be driven by buoyancy forcing. 

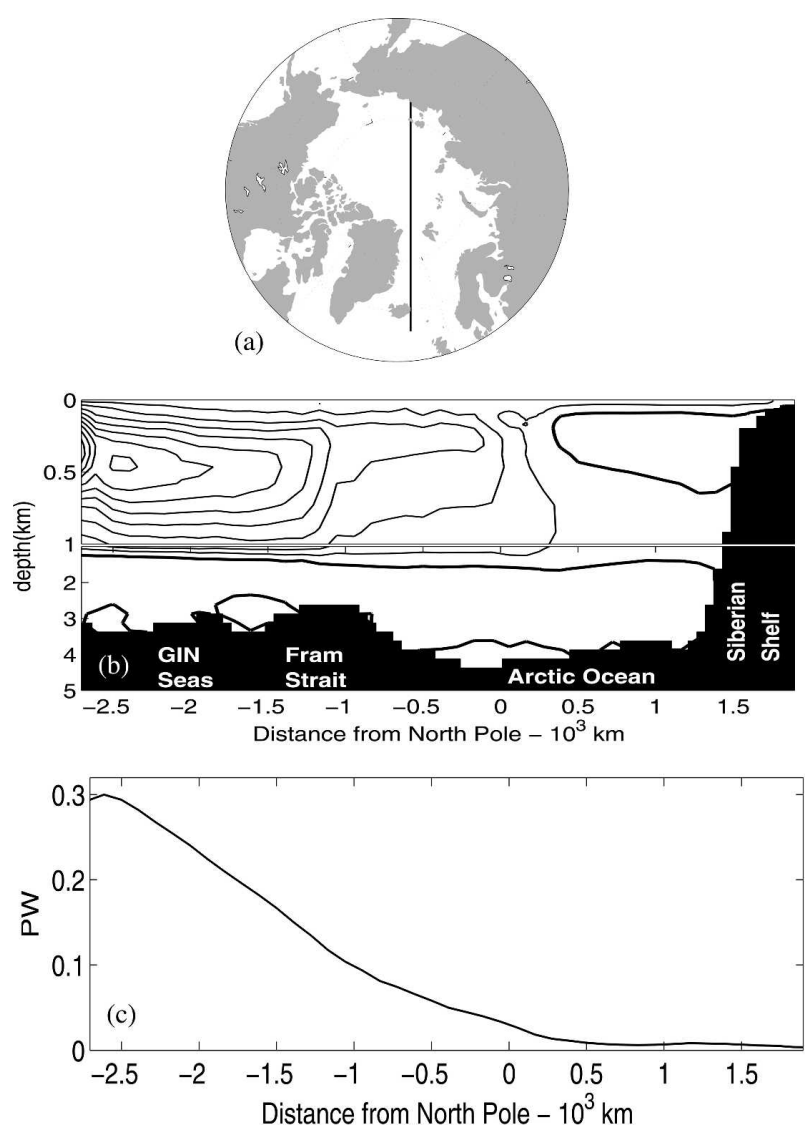

FIG. 10. Map of Arctic showing (a) the transect used for computing the overturning circulation, (b) streamfunction, and (c) heat transport in the control. Contour interval in (b) is $0.5 \mathrm{~Sv}$, heavy line denotes zero contour, light lines are positive.

In the face of increased precipitation and runoff at high latitudes and weaker air-sea fluxes in the subpolar North Atlantic at $\mathrm{CO}_{2}$ doubling (Bryan et al. 2006), it may seem unlikely that strengthened overturning and heat transport could be driven by the surface density flux. However, more than a decade ago, Aagaard and Carmack (1994) argued that ventilation in the Canadian Basin could increase if ice production increased on the Siberian shelves and in the Canadian Basin. Indeed ice production does increase in the central Arctic and Siberian shelf, as sea ice thins with increasing $\mathrm{CO}_{2}$ concentration. This counterintuitive relationship follows from the inverse dependence of heat conduction (and hence sea ice growth) on ice thickness. The relationship breaks down where the ocean-ice heat flux dominates over the conductive flux in controlling ice growth, such as where solar absorption in the ocean is high or turbulent mixing brings heat to the ice in the GIN seas and the Southern Ocean. Therefore we only expect ice production to increase with increasing $\mathrm{CO}_{2}$ in the central Arctic until ice-free conditions prevail during summer
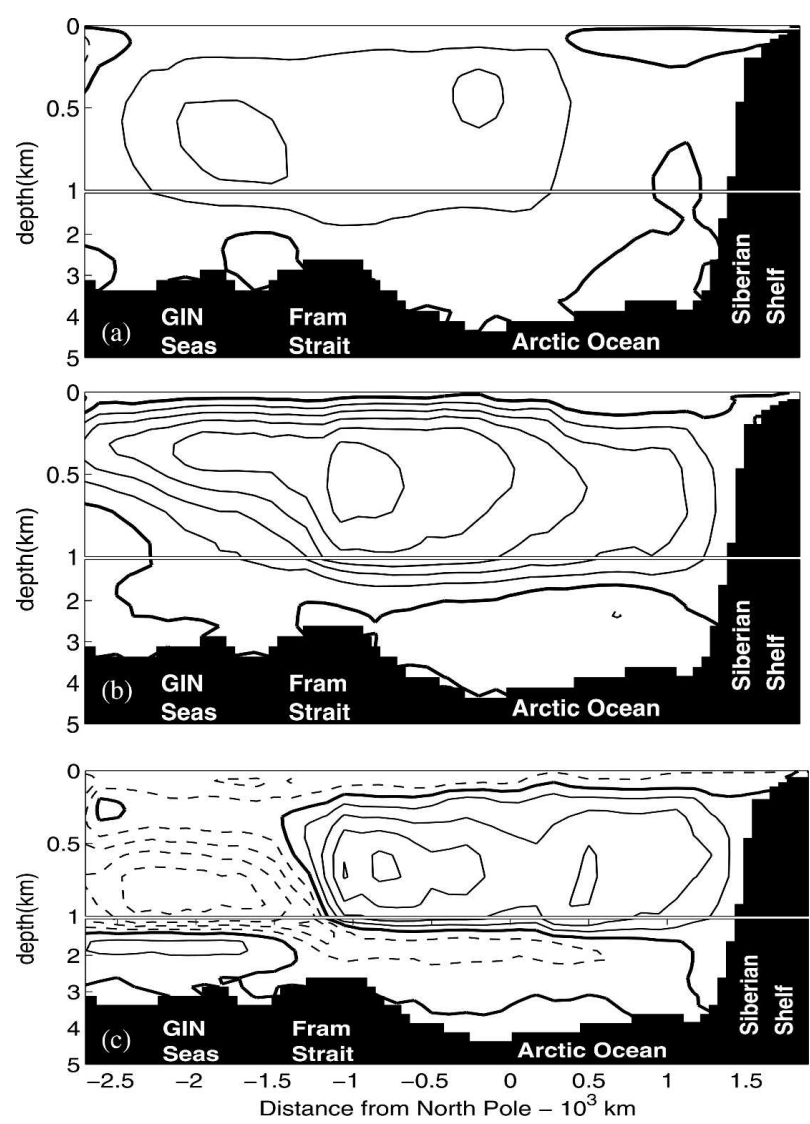

FIG. 11. Change in overturning circulation in the $\mathrm{CO}_{2}$ ramping experiment along the transect shown in Fig. 10a for 20-yr means centered about year (a) 30, (b) 50, and (c) 70. Carbon dioxide levels reach twice the 1990s level in (C). Contour interval is $0.1 \mathrm{~Sv}$, heavy line denotes zero, light solid (dashed) lines are positive (negative).

and into the fall. Figure 13a shows ice production does indeed increase in the central Arctic when $\mathrm{CO}_{2}$ is increased. In fact the maximum increase in ice production occurs at about year 50 in the $\mathrm{CO}_{2}$ ramping experiments, which corresponds roughly with the time of maximum increase in the overturning circulations shown in Fig. 11.

Figure 13b shows that the change in ocean-ice flux in February is about $2 \mathrm{~W} \mathrm{~m}^{-2}$ higher near the North Pole and is in excess of $10 \mathrm{~W} \mathrm{~m}^{-2}$ along the ice edge in some regions. The ocean-ice heat flux (heat derived from turbulent mixing near the surface) increases where sea ice remains unmelted in the warmer climate. We chose the month of February in an attempt to eliminate as much as possible any change in heat storage from absorbed shortwave radiation the previous summer. Maykut and Untersteiner (1971) showed that an increase in ocean-ice heat flux of this size could have a devastating effect on the sea ice cover. Indeed it does. The dashed 

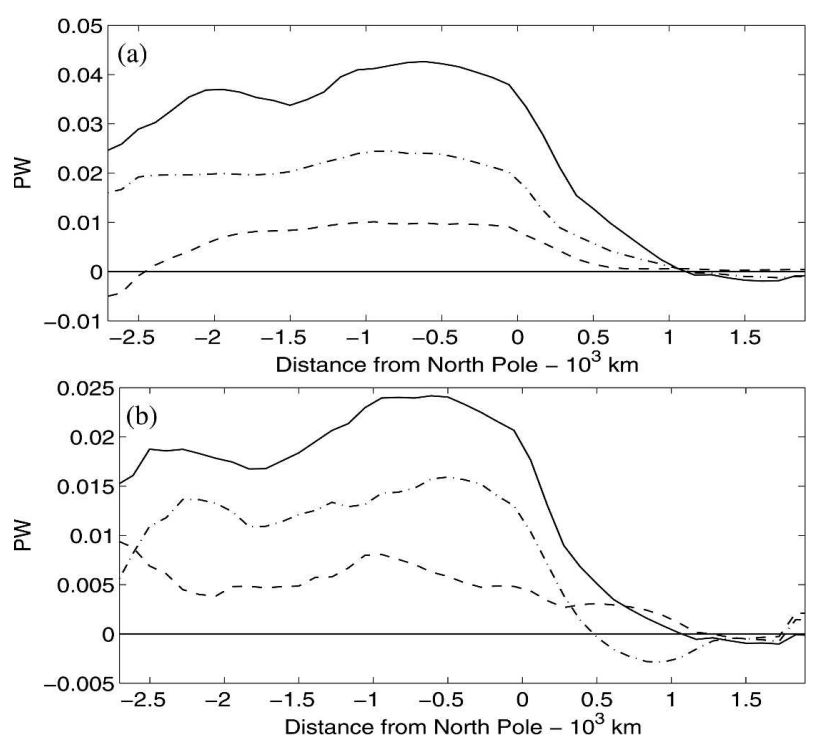

FIG. 12. (a) Change in heat transport in the $\mathrm{CO}_{2}$ ramping experiment along the transect shown in Fig. 10a for the same three time periods shown in Fig. 11, years 20-40 (dashed), years 40-60 (dot-dash), and years 60-80 (solid). (b) Change in heat transport (solid) and its components $\mathbf{v}^{\prime} T$ (dot-dash) and $\mathbf{v} T^{\prime}$ (dashed) for years $40-60$ of the $\mathrm{CO}_{2}$ ramp run, corresponds to overturning in Fig. 11b.

and solid lines in Fig. 13b indicate that the ice edge (defined as the $15 \%$ sea ice concentration contour) in February recedes most where the ice-ocean heat flux increases the most.

Both increased ice production and ocean surface heat loss in the Arctic Basin (see Fig. 5) contribute to a positive density flux anomaly in winter, but overall the density flux anomaly is negative (not shown) owing to increased precipitation and runoff in summertime. Nonetheless the ideal age of the ocean water decreases dramatically near the Siberian shelf (Fig. 13c), which indicates that convection strengthens along the shelf. We assume that this strengthened convection in turn causes strengthened overturning and heat transport into the Arctic Ocean, as described by (Marshall and Schott 1999).

Reducing the sea ice albedo warms the subsurface Arctic Ocean about $1 / 3$ as much as doubling $\mathrm{CO}_{2}$ for two reasons: 1) the sea ice response is smaller, resulting in smaller amplitude anomalies in ice production and surface heat loss, and 2) the lack of forcing over ice-free ocean fails to warm the waters imported into the Arctic.

\section{Discussion}

Reducing the sea ice albedo alone in CCSM3 creates a climate response that gives rise to strong ocean heat uptake in the Southern Ocean and modest ocean heat uptake in the subsurface Arctic Ocean. In turn, the surface air warming is highly hemispherically asymmetric - considerable in the Arctic and very little in the Antarctic.

In contrast, the equilibrium climate response to reducing the sea ice albedo in CCSM3 using a simple slab ocean formulation (which lacks a deep ocean) has much higher surface air warming in the Antarctic (see Fig. 14). The difference between the equilibrium (slab ocean) and transient (full ocean GCM) surface air warming (cf. curves in Fig. 14) is from ocean heat uptake. A portion of the subsurface Arctic Ocean warming maintains sea ice-free conditions in winter and enhances sea ice retreat and surface warming. The processes that give rise to deep ocean warming in the Southern Ocean also reduce the amount of ocean heat lost locally to the overlying atmosphere, which limits the surface warming in the Antarctic.

Deep ocean warming results from weakened convection in the Southern Ocean. Gregory (2000) and Huang et al. (2003) argued that convection is weakened because the ocean loses less heat to the warmer air above. However, Gregory (2000) pointed out the apparent contradiction in this conclusion with the lack of actual surface air warming. We find instead that convection is weakened mostly by local freshening at the surface through ice and ocean freshwater transport. Increased shortwave absorption as the ice retreats contributes somewhat as well, but only at the northern margin of the region where convection is weakened.

Many simple climate models approximate ocean heat uptake as a simple thermal diffusive process driven by the temperature difference of the surface and deep ocean, possibly with a parameterization for upwelling (Raper et al. 2001; Hansen et al. 2002; Sokolov et al. 2003). However, if the surface freshwater budget plays such a strong role in determining ocean heat uptake, these models may be missing important physics. We find reducing the sea ice albedo alone can initiate an increase in ocean heat uptake with little surface warming. Hence, ocean heat uptake may depend on sea ice characteristics, such as the albedo's dependence on temperature and ice thickness or the ice rheology. Raper et al. (2002) found that ocean heat uptake is more efficient in models with higher climate sensitivity. Raper et al. posited that the efficiency might be greater in models with greater high-latitude warming relative to the global mean. We suggest instead that ocean heat uptake is greater in models with higher sea ice retreat.

\section{Conclusions}

Two significant changes in ocean heat uptake occur in the vicinity of sea ice cover: A deep warming below 

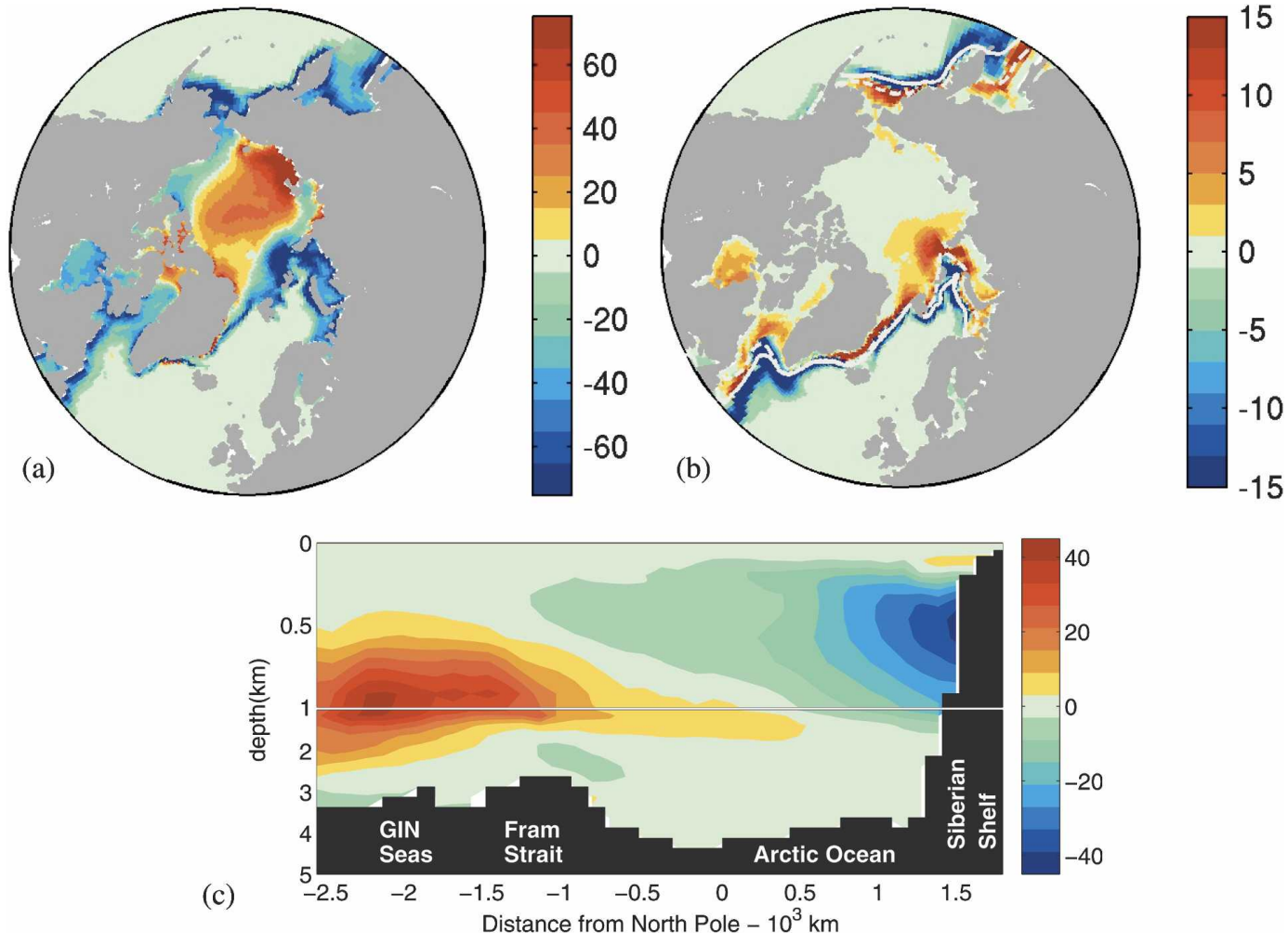

FIG. 13. Change in (a) annual ice production (excludes ice melt) in $\mathrm{cm}$ and (b) ocean-ice flux (positive sign indicates an increase toward the ice) in $\mathrm{W} \mathrm{m}^{-2}$ for February resulting from doubling $\mathrm{CO}_{2}$. (c) Change in ocean ideal age in yr from doubling $\mathrm{CO}_{2}$ along the transect shown in Fig. 10a.

about $500 \mathrm{~m}$ and extending down several kilometers in the Southern Ocean and warming in a $\sim 200$-m-thick layer just below the surface in the Arctic. These characteristics of the warming in the high-latitude oceans occur when the forcing is either from ramping $\mathrm{CO}_{2}$ or reducing sea ice albedo.

Changes in the Arctic Ocean are due to enhanced heat transport from the northern North Atlantic that is simultaneous with an increase in convection along the

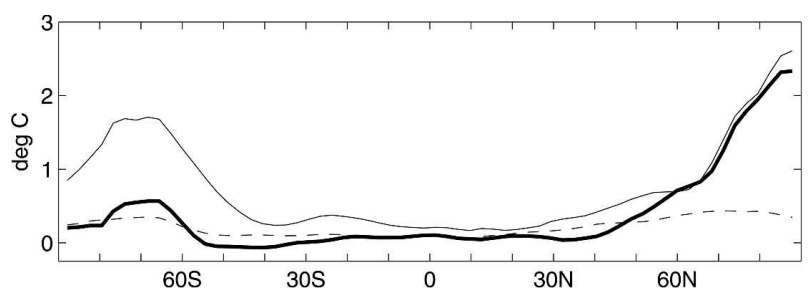

FIG. 14. Zonal means of the transient (heavy line, full OGCM) and equilibrium (light line, slab ocean) surface air warming in response to reducing the sea ice albedo. The dashed line is an estimate of the $95 \%$ significance level for a difference of means test where each year is assumed to be independent of the next and each latitude is assumed to have two independent spatial degrees of freedom.
Siberian shelves. Shelf convection appears to be driven by increased heat loss and ice production, as the ice cover changes from perennial to first year (thinner ice grows faster). In contrast, convection decreases in the GIN seas and south of the Iceland-Scotland Ridge (also see Bryan et al. 2006). While the meridional overturning circulation south of the Iceland-Scotland Ridge is weaker, overturning strengthens into the Arctic Ocean.

Eventually when future $\mathrm{CO}_{2}$ levels increase beyond doubling, less and less sea ice grows in winter. At some point, the overturning circulation into the Arctic decreases and the enhanced northward heat transport into the Arctic slowly declines again (but the ice does not return to present-day extent). Antarctic sea ice is nearly all first-year ice at present, so it is already in the mode where increasing $\mathrm{CO}_{2}$ reduces ice production (except where there is increased ice export along the coasts).

Enhanced deep ocean heat uptake in the Southern Ocean is initiated by weakened convection at the surface. Reducing the sea ice albedo weakens convection very efficiently, in spite of very little surface air warming. Our results show that surface air warming does not directly cause convection to weaken in our experi- 
ments. Instead, surface waters become more stable mostly from freshening owing to changes in ice and ocean freshwater transport. Convection weakens in several large areas in the Antarctic, and it is slightly enhanced at the wintertime sea ice edge in the Atlantic sector. Below about $500 \mathrm{~m}$, these changes in convection give rise to weakened vertical and meridional temperature gradients in the Southern Ocean, which significantly reduce isopycnal diffusion of heat upward around Antarctica.

The same mechanisms that give rise to oceanic warming at either pole occur in response to increasing $\mathrm{CO}_{2}$ or reducing the sea ice albedo. Our results show that sea ice strongly contributes to polar ocean warming.

Acknowledgments. This paper benefited from reviews by Elizabeth Hunke and one anonymous reviewer. The authors gratefully acknowledge the support of the National Science Foundation through Grants ATM0304662 (CMB), OPP0454843 (CMB and RAW), and OPP0084273 (MMH). Computational facilities have been provided by the National Center for Atmospheric Research (NCAR). Two of the model integrations were performed by CRIEPI using the Earth Simulator through the international research consortium of CRIEPI, NCAR, and LANL under the Project for Sustainable Coexistence of Human Nature and the Earth of the Japanese Ministry of Education, Culture, Sports, Science and Technology.

\section{REFERENCES}

Aagaard, K., and E. C. Carmack, 1994: The Arctic Ocean and climate: A perspective. The Polar Oceans and their Role in Shaping the Global Environment, Geophys. Monogr., Vol. 85, Amer. Geophys. Union, 5-20.

Briegleb, B. P., E. C. Hunke, C. M. Bitz, W. H. Lipscomb, M. M. Holland, J. L. Schramm, and R. E. Moritz, 2004: The sea ice simulation of CCSM2. NCAR Tech. Rep. NCAR-TN-455, Boulder, CO, 34 pp.

Bryan, F., G. Danabasoglu, N. Nakashiki, Y. Yoshida, D.-H. Kim, J. Tsutsui, and S. Doney, 2006: Response of North Atlantic thermohaline circulation and ventilation to increasing carbon dioxide in CCSM3. J. Climate, 19, 2382-2397.

Collins, W. D., and Coauthors, 2006: The Community Climate System Model version 3 (CCSM3). J. Climate, 19, 2122-2143.

Flato, G. M., G. J. Boer, W. G. Lee, N. A. McFarlane, D. Ramsden, M. C. Reader, and A. J. Weaver, 2000: The Canadian Centre for Climate Modelling and Analysis global coupled model and its climate. Climate Dyn., 16, 451-467.

Gent, P. R., and G. Danabasoglu, 2004: Heat uptake and the ther- mohaline circulation in the Community Climate System Model, version 2. J. Climate, 17, 4058-4069.

Gordon, A. L., and B. A. Huber, 1984: Thermohaline stratification below the Southern Ocean sea ice. J. Geophys. Res., 89, 641-648.

Gregory, J. M., 2000: Vertical heat transport in the ocean and their effect on time-dependent climate change. Climate Dyn., 16, 501-515.

Hansen, J., and L. Nazarenko, 2004: Soot climate forcing via snow and ice albedos. Proc. Natl. Acad. Sci. USA, 101, 423-428.

_ , and Coauthors, 2002: Climate forcings in Goddard Institute for Space Studies SI2000 simulations. J. Geophys. Res., 107, 4347, doi:10.1029/2001JD001143.

Holland, M. M., and C. M. Bitz, 2003: Polar amplification of climate change in the Coupled Model Intercomparison Project. Climate Dyn., 21, 221-232.

- - — E. C. Hunke, W. H. Lipscomb, and J. L. Schramm, 2006: Influence of the sea ice thickness distribution on polar climate in CCSM3. J. Climate, 19, 2398-2414.

Houghton, J. T., and Coauthors, 2001: Climate Change 2001: The Scientific Basis. Cambridge University Press, 944 pp.

Huang, B., P. H. Stone, A. P. Sokolov, and I. V. Kamenkovich, 2003: The deep-ocean heat uptake in transient climate change. J. Climate, 16, 1352-1363.

Ingram, W. J., C. A. Wilson, and J. Mitchell, 1989: Modeling climate change: An assessment of sea ice and surface albedo feedbacks. J. Geophys. Res., 94, 8609-8622.

Manabe, S., R. J. Stouffer, M. J. Spellman, and K. Bryan, 1991: Transient responses of a coupled ocean-atmosphere model to gradual changes of atmospheric $\mathrm{CO}_{2}$. Part I: Annual mean response. J. Climate, 4, 785-818.

Marshall, J., and F. Schott, 1999: Open-ocean convection: Observations, theory and models. Rev. Geophys., 37, 1-64.

Martinson, D., 1990: Evolution of the Southern Ocean winter mixed layer and sea ice-open ocean deep-water formation and ventilation. J. Geophys. Res., 95, 11 641-11 654.

Maykut, G. A., and N. Untersteiner, 1971: Some results from a time-dependent thermodynamic model of sea ice. J. Geophys. Res., 76, 1550-1575.

Meehl, G. A., and Coauthors, 2006: Climate change projections for the twenty-first century and climate change commitment in the CCSM3. J. Climate, 19, 2597-2616.

Raper, S. C. B., J. M. Gregory, and T. J. Osborn, 2001: Use of an upwelling-diffusion energy-balance climate model to simulate and diagnose A/OGCM results. Climate Dyn., 17, 601613.

— - — , and R. J. Stouffer, 2002: The role of climate sensitivity and ocean heat uptake on AOGCM transient temperature response. J. Climate, 15, 124-130.

Sokolov, A. P., C. E. Forest, and P. H. Stone, 2003: Comparing oceanic heat uptake in AOGCM transient climate change experiments. J. Climate, 16, 1573-1582.

Wiebe, E. C., and A. Weaver, 1999: On the sensitivity of global warming experiments to the parameterisation of sub-grid scale ocean mixing. Climate Dyn., 15, 875-893. 